\title{
DESENVOLVIMENTO DE PROJETOS E(M) EDUCAÇÃO PARA A CIDADANIA - O CASO DO PROGRAMA DE APOIO À EXTENSÃO DO IFRN
}

\author{
João Paulo de Oliveira; Conceição Leal Costa \\ jprussasce@gmail.com; mclc@uevora.pt \\ Universidade de Évora \\ DOI: 10.15628/rbept.2018.7085
}

Artigo submetido em fev/2018 e aceito em mar/2018

\section{RESUMO}

No Brasil, a Lei 11.892/2008 incorporou a extensão à educação profissional e tecnológica nos Institutos Federais, com contornos idênticos à das universidades. No entanto, a extensão no âmbito da Rede Federal de Educação Profissional e Tecnológica apresenta algumas especificidades fazendo-se necessário compreender o seu significado, os desafios educacionais que lança e também suas possibilidades de implementação. Nesse sentido, partilhamos, nesse texto, os resultados parciais de um estudo, o Caso do Programa de Apoio Institucional à Extensão (PAIE) do IFRN (Campus Mossoró), realizado no âmbito da Tese de Doutoramento em Ciências da Educação (Universidade de Évora, Portugal). Assim, os objetivos desse artigo consistem em discutir e refletir sobre como e quais são os ganhos relacionados à educação para a cidadania que se desenvolvem durante a participação de alunos extensionistas do Ensino Médio Integrado em projetos de extensão fomentados pelo PAIE. Para tanto, consideramos a realização de observações e apontamentos em notas de campo feitas entre maio a dezembro de 2017 e embasamos a nossa partilha, fazendo ressaltar alguns autores, como é o caso de Freire (2015), Sousa (2001), Tavares (2001), Cover (2014), Pacheco (2011), Xavier et al (2013), Cortina (2005), Nussbaum (2015), Afonso (2014) e Simons (2014). Os vídeos gravados e as notas nos permitiram perceber como se processa o desenvolvimento das relações entre alunos extensionistas/alunos externos durante a execução de projetos de extensão do Programa de Apoio Institucional à Extensão do IFRN (Campus Mossoró). Essa relação se desenvolve em função da inserção dos alunos extensionistas em contextos ainda não vivenciados pelos alunos do Ensino Médio Integrado, possibilitando assim o seu desenvolvimento com base em atitudes e experiências que podemos relacionar com uma educação para a cidadania. Portanto, podemos considerar que o PAIE é uma política de fomento à extensão no IFRN que contribui para a construção da extensão como uma prática educativa por meio da interação com a comunidade externa. 0 nosso estudo vai apontando possibilidades para isso acontecer e mostra que podem ser programas e projetos realizados em contexto real e comunitário. No 
entanto, é preciso não dissociar a extensão como princípio educativo das dimensões do ensino e da pesquisa, para esbater tradicionais preponderâncias e fragmentações de saberes, o que parece conseguir-se com sucesso se existir participação e cooperação.

Palavras-chave: Programa de Apoio Institucional à Extensão (PAIE); Ensino Médio Integrado; Projetos; Comunidades; Educação para a Cidadania.

\section{DEVELOPMENT OF PROJECTS AND (IN) EDUCATION FOR CITIZENSHIP - THE CASE OF THE IFRN EXTENSION SUPPORT PROGRAM}

\section{ABSTRACT}

In Brazil, the Law 11.892/2008 incorporated the extension to the professional and technological education in the Federal Institutes, with identical contours to the universities. However, the extension in the Federal Network of Professional and Technological Education presents some specificities making the understanding of its meaning, the educational challenges and their possibilities of implementation necessary. In this sense, we share in this text, the partial results of a study, the Case of the Programa de Apoio Institucional à Extensão (Institutional Support to Extension Program - PAIE) of the IFRN (Campus Mossoró), carried in the activities of the Doctoral Thesis in Education Sciences (Évora University, Portugal). Thus, the objectives of the article are to discuss and publicize how and what are the gains related to citizenship education that are developed during the participation of extension students of Integrated High School in extension projects fostered by PAIE. To do it, we considered observations and notes in field notes between May and December 2017 and support our sharing, emphasizing some authors, such as Freire (2015), Sousa (2001), Tavares (2001), Cover (2014), Pacheco (2011), Xavier et al (2013), Cortina (2005), Nussbaum (2015), Afonso (2014) and Simons (2014). The recorded videos and the notes enabled us to understand how the development of the relations between extension students / external students during the execution of projects of extension of the Programa de Apoio Institucional à Extensão (Institutional Support to Extension Program PAIE) of the IFRN (Campus Mossoró). This relationship is developed as a result of the inclusion of extensive students in contexts not yet experienced by the students of the Integrated High School, enabling their development based on attitudes and experiences that we can relate to an education for a citizenship. Therefore, we can consider that the PAIE is a policy to promote extension in the IFRN that contributes to the construction of extension as an educational practice through interaction with an outside community. Our study points out possibilities for this and shows that it can be programs and projects carried out in a real and community 
context. However, it is necessary not to dissociate an extension as an educational principle from the dimensions of teaching and research, to blur traditional preponderance and fragmentation of knowledge, which seems to be successfully achieved.

Keywords: Institutional Support to Extension Program (PAIE); Integrated High School; Projects; Communities; Education for Citizenship.

\section{INTRODUÇÃO}

A extensão é uma prática educacional implementada inicialmente nas universidades com o objetivo de levar conhecimento à comunidade externa por meio de atividades que buscavam envolver docentes e discentes. Ao longo do tempo, a perspectiva de transmissão de conteúdos tem migrado para a ideia de construção de conhecimentos entre estudantes extensionistas e comunidade externa, ou seja, a extensão tende a ser compreendida como uma prática educativa que se desenvolve por meio da interação com a comunidade externa em um processo dialógico de troca de conhecimentos. Entretanto, essa visão ainda é incipiente, visto que as perspectivas assistencialista e de prestação de serviços conduziram, durante décadas, as políticas extensionistas.

A extensão, compreendida apenas como um ato de transferência de conhecimento perde seu sentido enquanto ato educativo, pois os participantes da comunidade externa passam a ser compartimentos para o depósito de informações, como se fossem seres inanimados, passivos e inertes às ações desenvolvidas.

Dessa forma, faz-se necessário compreender o significado da extensão como uma prática educativa, suas possibilidades e os desafios de sua implementação no âmbito da educação profissional e tecnológica. 0 sentido atribuído à extensão como prática educativa precisa ser consolidado para superarmos a perspectiva de educação bancária e construirmos uma visão que compreende a relação instituição-sociedade como um processo de construção recíproca do conhecimento. Compreendida dessa forma, a extensão conduz ao desenvolvimento de processos educativos que ajudam na formação dos educandos e, ao mesmo tempo, dos participantes das ações de extensão. Para tanto, é necessária implementação de políticas de fomento que possibilitem o desenvolvimento de atividades de extensão com essa perspectiva, especialmente no âmbito do Ensino Médio Integrado que tem como premissa a formação humana integral do aluno. Como prática educativa, o dialogismo proporcionado pela extensão, pode contribuir com a construção de valores relacionados à educação para a cidadania.

Assim, buscamos nesse artigo discutir e refletir sobre como e quais são os ganhos relacionados à educação para a cidadania desenvolvidos durante a participação de alunos extensionistas do Ensino Médio Integrado em projetos de extensão fomentados pelo Programa de Apoio Institucional à Extensão do IFRN. Abordar a extensão como prática educativa é, 
portanto, compreender que a educação para a cidadania não se desenvolve apenas nos bancos escolares, mas também por meio das relações sociais que se estabelecem com os segmentos sociais. Com isso, a comunidade externa, deixa de ser pensada como um espaço para consumo do conhecimento produzido pela instituição escolar e passa a ser um local para a produção de conhecimento por meio de uma relação dialógica entre educandos e sociedade.

\section{METODOLOGIA}

Esse estudo é o resultado parcial da tese que está em desenvolvimento no âmbito do Programa de Doutoramento em Ciências da Educação da Universidade de Évora (Portugal). Para este artigo, buscamos conduzir a discussão a partir de um estudo de caso do Programa de Apoio Institucional à Extensão (PAIE) no IFRN (Campus Mossoró). Para tanto tivemos como base a realização de observações e apontamentos em notas de campo feitas entre maio a dezembro de 2017, além do embasamento teórico de alguns autores como Freire (2015), Sousa (2001), Tavares (2001), Cover (2014), Pacheco (2011), Xavier et al (2013), Cortina (2005), Nussbaum (2015), Afonso (2014) e Simons (2014).

O Programa de Apoio Institucional à Extensão (PAIE), em função dos seus objetivos e dinâmica, se constitui como uma política institucional que fomenta o desenvolvimento de projetos de extensão que podem contribuir com a promoção da educação para a cidadania dos estudantes do Ensino Médio Integrado. Dessa forma, fomos instigados a compreender a seguinte questão: como e quais são os valores relacionados à educação para a cidadania no Ensino Médio Integrado do IFRN (Campus Mossoró) desenvolvidos pelos os alunos extensionistas no Programa de Apoio Institucional à Extensão (PAIE)?

Assim, buscamos desenvolver uma pesquisa a nível de doutoramento em Ciências da Educação na Universidade de Évora com o intuito de perceber como o PAIE contribui com a educação para a cidadania dos estudantes do Ensino Médio Integrado do IFRN ao fomentar o desenvolvimento de projetos de extensão. Para tanto, realizamos nossa pesquisa no Campus Mossoró por meio do acompanhamento de dois projetos de extensão, desenvolvidos entre maio e dezembro de 2017, fomentados pelo Edital nº 002/2017/PROEX do PAIE.

Considerando-se os objetivos propostos para o estudo, adotamos os seguintes critérios de escolha dos projetos quem integram a nossa pesquisa: (C1) os alunos participantes estão matriculados no Ensino Médio Integrado? (C2) Os projetos possibilitam a participação de pessoas da comunidade externa durante sua execução? (C3) os projetos apresentem perspectiva de extensão como princípio educativo? (C4) A área temática apresenta-se pertinente com às questões atuais?

Após a leitura da proposta formal dos cincos projetos que foram aprovados pelo Edital 002/2017/PROEX que regulamentou o PAIE no ano de 2017, procedemos à aplicação dos critérios estabelecidos para a escolha dos projetos que se tornaram as unidades de análise integradas do caso. 
Assim, delimitamos o caso e aplicamos os critérios descritos acima para chegarmos aos projetos que serviram como as unidades integradas de análise os quais, juntamente com outros elementos, contribuíram para a compreensão do caso. Os critérios aplicados apontaram para três projetos, mas, em função de problemas na execução de um dos projetos, utilizamos no estudo somente dois projetos de extensão como unidades integradas de análise.

O plano de recolha de dados incluiu: análise documental: edital 002/2017/PROEX e dos projetos aprovados pelo PAIE em Mossoró; contato com os coordenadores dos projetos selecionados; observação direta dos seguintes eventos: reunião de gestores, planejamento de ações entre coordenadores e estudantes dos projetos selecionados, ações realizadas pelos estudantes para fazer a interação com a comunidade e ações junto à comunidade; elaboração de guião de entrevistas; realização de entrevistas com pró-reitora de extensão, coordenador de extensão, coordenadores de projetos do PAIE e estudantes participantes do PAIE.

Nesse artigo, nos deteremos à apresentação e discussão dos resultados parciais das obervações diretas realizadas no período de maio a dezembro de 2017 junto aos dois projetos de extensão realizados no IFRN (Campus Mossoró) que serviram como unidades de análise integradas do Programa de Apoio Institucional à Extensão (PAIE).

A observação direta em um estudo de caso visa descrever detalhadamente algum evento que ocorre em um contexto e deve registrar o tempo, local, incidentes específicos, transações e diálogos dos envolvidos (Simons, 2014). A recolha de informações por meio dessa técnica é bastante fidedigna, visto que os dados não estão condicionados à opinião e aos pontos de vista dos informantes, como no caso de entrevistas (Afonso, 2014). Em virtude de sua relevância, a observação direta foi uma técnica fundamental de recolha de dados para o desenvolvimento dessa pesquisa.

Os dados das observações diretas foram registrados por meio de vídeos, fotos e através de notas de campo, em formulário próprio pensado para este fim considerando o contexto estudado. As notas tinham o intuito de conhecer, da maneira mais detalhada possível, todas as atividades desenvolvidas pelos estudantes participantes do projeto de extensão.

As notas incluíram, para além dos dados básicos de identificação, a sequência de atos que ocorreram, a descrição dos fatos ocorridos e as impressões e sentimentos observados pelo pesquisador. Buscamos descrever todos os detalhes dos ambientes onde as ações aconteceram, especialmente dos espaços fora da escola para onde o estudante se deslocou a fim de realizar alguma ação do projeto de extensão. A descrição incluía as ações e atitudes dos estudantes diante da comunidade externa, anotações sobre suas decisões diante dos contextos previsíveis e imprevisíveis, bem como suas formas de lidar com os aspectos sociais transmitidos na comunidade.

Os vídeos foram gravados e as ações acompanhadas por meio de uma grelha de observações estruturada em sete eixos de análise: relação organizacional, relação atividade/ projeto, relação atividade/conteúdo abordado, relação atividade/extensão, atividade/alunos extensionistas, relação aluno extensionista $\mathrm{x}$ alunos da comunidade externa (Educação para $\mathrm{a}$ 
cidadania), ações e reações dos participantes da comunidade externa.

Cada projeto de extensão tinha uma particularidade e para definirmos quais ações seriam observadas precisamos ter em mente os objetivos do estudo. Logo, toda ação que envolvia um contato entre os estudantes e a comunidade se mostrava relevante, visto que a nossa pesquisa defende que, por meio dessa relação é possível o desenvolvimento da educação para a cidadania dos alunos do Ensino Médio Integrado. Assim, procedemos às observações dos dois projetos.

A primeira unidade de análise integrada do caso observada foi o projeto, denominado P5, que consistia em um projeto de informática desenvolvido por quatro alunos/as do Curso Técnico de Nível Médio em Informática na forma integrada junto aos alunos de escolas públicas municipais e estaduais do município de Mossoró. Esse projeto foi o que mais manteve relação com a comunidade, pois os alunos passaram aproximadamente quatro meses desenvolvendo atividades diretas com a comunidade externa por meio de um curso de informática básica com duração de 80h.

A segunda unidade de análise integrada do caso que fizemos observação foi o projeto, denominado $\mathrm{P} 1$, que consistia em um projeto de extensão desenvolvido por cinco alunos/as do Curso Técnico de Nível Médio em Mecânica na forma Integrado. Esse projeto tinha como objetivo possibilitar o entendimento dos conceitos básicos da mecânica dos fluídos por meio de experimentos práticos junto a alunos de escolas públicas municipais e estaduais. Esse projeto desenvolvia atividades de curta duração com alunos de escolas públicas, por meio de minicursos com duração de 6 h.

\section{EXTENSÃO COMO PRÁTICA DE DESENVOLVIMENTO DA EDUCAÇÃO PARA A CIDADANIA NO ENSINO MÉDIO INTEGRADO}

A gênese da extensão passa por uma compreensão que a associava ao assistencialismo ou à prestação de serviços e se incorporou à história das universidades ao longo do tempo como um instrumento de potencialização das ações universitárias. A extensão coloca o educando em contato direto com a sociedade, o que faz dessa atividade pedagógica um meio prático para a constituição da educação para a cidadania dos alunos extensionistas. Tendo em vista o fato da extensão está imbricada às universidades, a literatura que versa sobre o assunto apresenta-a de forma associada ao mundo universitário, mas o conceito e os princípios da extensão, considerando-se algumas distinções e peculiaridades, tem a mesma representatividade para a educação profissional e tecnológica de nível médio.

Freire (2015) questiona a acepção do termo extensão pela universidade, por compreender que a ideia de estender/alcançar não contemplava a dimensão que deveria comportar dentro dos processos educativos. A educação é um processo que envolve estritamente relações humanas e como tal é preciso considerar as diferentes maneiras de dialogar para que se possa desenvolver novas possibilidades de aprendizado. A extensão, compreendida apenas como um 
ato de transferência de conhecimento perde seu sentido enquanto ato educativo, pois "[...] 0 conhecimento não se estende do que se julga sabedor até aqueles se julgam não saberem; o conhecimento se constitui nas relações homem-mundo, relações de transformação, e se aperfeiçoa na problematização crítica dessas relações". (FREIRE, 2015, p. 42-3).

Dessa forma, não dá para comportar dentro de um processo educativo apenas a perspectiva de estender um conhecimento, pois o diálogo é próprio do ser humano e por meio dele é possível travar relações que podem conduzir a um percurso multidirecional de troca de conhecimentos envolvendo todos os sujeitos participantes do processo de aprendizagem. Segundo Freire (2015, p. 65), o diálogo "[...] é a problematização do próprio conhecimento em sua indiscutível reação com a realidade concreta [...] para melhor compreendê-la, explicá-la, transformá-la". A extensão em uma perspectiva dialógica deve, portanto, manter uma relação de igualdade entre os extensionistas vinculados a uma instituição de educação formal e os membros da comunidade externa que participam da atividade ou projeto de extensão. 0 diálogo e a problematização conscientizam e podem desenvolver uma postura crítica da qual resulta a percepção de que é possível contribuir com a transformação da realidade (FREIRE, 2015). Esse processo dinâmico é capaz de desenvolver a educação para a cidadania dos alunos participantes de atividades de extensão.

Compreendida dessa forma, a extensão conduz ao desenvolvimento de processos educativos que contribuem com a formação dos educandos e, ao mesmo tempo, dos participantes das ações de extensão. A partir do momento em que o educando se confronta e conhece realidades específicas, inicia-se, mesmo que de maneira intrínseca, um processo de produção de conhecimento. Instigado à reflexão sobre a realidade que the é apresentada, o educando coloca-se em posição de agente de transformação e internaliza o interesse de participar ou de desenvolver outras ações que possam contribuir com a mudança de realidade da comunidade.

Assim, a extensão é considerada um processo educativo e não uma prática assistencialista ou um mecanismo de prestação de serviços que deve ser desenvolvido de maneira integrada ao ensino e à pesquisa. Esse processo educativo desenvolve-se a partir de uma relação dialógica, conforme defendido por Freire (2015), entre a instituição educacional e a sociedade, de maneira a criar um fluxo que possibilita a troca de conhecimentos e proporciona aos docentes e discentes novos aprendizados que não seriam plenamente alcançados apenas nos intramuros da instituição. Ao inserir o educando no contexto da realidade de uma comunidade, a extensão leva-o à problematização sobre o seu papel no mundo e à reflexão sobre como agir com os demais diante da situação sobre a qual foi confrontado.

A extensão pode ser entendida como uma prática acadêmica que visa integrar-se com a sociedade a partir da produção do conhecimento gerado pelo ensino e a pesquisa. Essa produção não se dá apenas nos bancos escolares, mas por meio das diferentes relações que se estabelecem com os segmentos sociais, ou seja, a comunidade não é um setor social que vai apenas consumir ou usufruir dos conhecimentos produzidos pela instituição escolar, mas ao contrário, vai tornar esse conhecimento um ponto de partida para a construção de uma relação 
dialógica entre educandos e público das ações de extensão.

Corroborando com essa visão, Tavares (2001) reitera que a extensão como uma ação articulada ao ensino e à pesquisa, incentiva a criação e recriação de conhecimentos que estimulam e fortalecem a pesquisa, além de possibilitar novas práticas interdisciplinares de ensino, pautadas em um novo conceito de sala de aula que considera outros espaços para a realização do processo histórico-social.

O educando insere-se em uma realidade com o objetivo de contribuir com seu desenvolvimento. Em virtude do seu estreito contato com a sociedade, associa suas ações ao resgate da cidadania dos setores populares, mas compreendida como um movimento dialógico, uma via de mão dupla na construção do conhecimento, podemos afirmar que, o desenvolvimento de ações de extensão contribui também com a construção da educação para a cidadania dos educandos participantes. Na opinião de Sousa (2001), a extensão é um instrumento de interação para a efetivação do compromisso social que a instituição tem com o seu meio, a partir da integração das práticas acadêmicas do ensino e da pesquisa.

Sousa (2001) reforça ainda que o ponto de partida para construção do conhecimento se dá a partir das relações que os homens desenvolvem nos diferentes ambientes sociais e, dessa forma, as instituições formadoras não devem ignorar o ambiente externo à instituição, pois ele também contribui para a formação dos educandos. Isso significa que, atuando sobre a mudança de determinadas circunstâncias, o sujeito também pode ser transformado por estas mesmas circunstâncias (SOUSA, 2001), ou seja, à medida que ele transforma também é transformado. As visões de mundo, as histórias de vida e o conhecimento empírico dos sujeitos participantes das ações de extensão se interligam à identidade dos educandos e proporcionam uma forma de aprendizado que não seria possível apenas pelo ensino e a pesquisa. Assim, a extensão assume uma função que a torna um elemento de extrema relevância na formação humana integral dos estudantes do ensino médio integrado. Entretanto, não deve ficar restrita apenas aos setores necessitados, pois assim irá perpetuar seu cunho assistencialista e não deve apenas deter-se à prestação de serviços por meio de convênios institucionais, mas sim ser institucionalizada como um processo acadêmico que atende a todos os segmentos da sociedade.

Essa visão se justifica, especialmente, em virtude das constantes mudanças ocorridas em termos sociais, econômicos, políticos e tecnológicos que presenciamos no início do século XXI no Brasil e no mundo. A instituição da Rede Federal de Educação Profissional, Científica e Tecnológica e a criação dos Institutos Federais de Educação, Ciência e Tecnologia se inserem nesse contexto de transformações e conquistas sociais perpetrados pelos governos brasileiros no período de 2003 a 2016 (644 em funcionamento).

Nesse contexto, a extensão assume um papel de destaque, pois os Institutos Federais nasceram como uma instituição social comprometida com todos e não exclusivamente com os setores dominantes na perspectiva de formar "[...] cidadãos como agentes políticos capazes de ultrapassar obstáculos, pensar e agir em favor de transformações políticas, econômicas e sociais imprescindíveis para a construção de outro mundo possível." (PACHECO, 2011, p. 29). Cover (2014) 
relembra ainda que, ao contrário das universidades, os Institutos Federais de Educação, Ciência e Tecnologia, além de oferecerem cursos superiores, por lei, devem garantir que cinquenta por cento das vagas sejam ocupadas pelos alunos do ensino fundamental em cursos integrados de nível médio. Com isso, temos um público jovem que inicia seus estudos no ensino médio e que estão regidos pelo tripé ensino, pesquisa e extensão (COVER, 2014).

Nesse cenário, o projeto político-pedagógico tem o desafio de formar sujeitos integralmente, capazes de atuarem profissionalmente e de se compreenderem como cidadãos capazes de transformar a sociedade onde estão inseridos. Tal perspectiva se coaduna com a visão de Freire (1996), ao afirmar que uma das tarefas mais relevantes da prática educativo-crítica é fazer com que os educandos, a partir das relações com os outros, possam desenvolver experiências que Ihes possibilitem assumir-se como um ser social e histórico capaz de criar, transformar e de se reconhecer como agente de transformação. Os Institutos Federais, que integram a Educação Profissional e Tecnológica, podem propiciar essa formação, com vistas à educação para a cidadania durante o ensino médio, mediada pela extensão, que necessariamente, pressupõe a realização de práticas interacionistas na comunidade para que haja a partilha e a construção de novos saberes.

Segundo Xavier et al. (2013, p.13), "por meio da extensão, os Institutos poderão proceder à difusão, à socialização e à democratização do conhecimento produzido e existente nos mesmos". Isso implica que a extensão deve se tornar uma prática integrante da educação profissional e tecnológica, uma vez que essa foi reestruturada com um caráter transformador para o desenvolvimento humano e social.

Nesse sentido, o Instituto Federal do Rio Grande do Norte (IFRN), tomando como base a Lei no 11.892 de 29/12/2008, a qual determinou que um dos objetivos dos Institutos é "desenvolver atividades de extensão de acordo com os princípios e finalidades da educação profissional e tecnológica, em articulação com o mundo do trabalho e os segmentos sociais, e com ênfase na produção, desenvolvimento e difusão de conhecimentos científicos e tecnológicos" (Brasil, 2008), implantou em 2011 o Programa de Apoio Institucional à Extensão (PAIE) que será discutido a seguir.

\section{PROGRAMA DE APOIO INSTITUCIONAL À EXTENSÃO (PAIE) DO IFRN: PRÁTICA DE DESENVOLVIMENTO DA EDUCAÇÃO PARA A CIDADANIA NO ENSINO MÉDIO INTEGRADO}

O Programa de Apoio Institucional à Extensão (PAIE) está previsto na Resolução n 35/2006CD, de 22 de novembro de 2006 do CEFET/RN como uma das ações de extensão possíveis de serem desenvolvidas no âmbito do IFRN. 0 art. $2^{\circ}$ da Resolução n 35/2006-CD define programa como: "conjunto de ações de extensão de caráter orgânico-institucional, com clareza de diretrizes e orientadas a um objetivo comum. Na prática, são formas de articulação de ações e outras 
ações existentes (cursos, eventos e prestação de serviços) em uma grande ação de médio e longo prazo. " (Resolução n 35/2006-CD)

As diretrizes do PAIE se fundamentam no art. 31 da Resolução nº 66/2009-IFRN que define as ações de extensão no IFRN como: “[...] um processo educativo, científico, artístico-cultural e desportivo que se articulam ao ensino e à pesquisa de forma indissociável, com o objetivo de intensificar uma relação transformadora entre o Instituto Federal de Educação, Ciência e Tecnologia do Rio Grande do Norte e a sociedade. " (Resolução nº 66/2009-IFRN)

Conforme discutimos no tópico anterior, a extensão como um processo educativo consiste em uma atividade pedagógica capaz de levar à produção de novos conhecimentos e aprendizados por meio da interação entre estudantes do IFRN e comunidade externa. Dessa forma, estamos intensificando o processo de transformação social, pois possibilita-se aos estudantes a sua imersão em realidades diversas, impulsionando-os à reflexão e desenvolvendo alguns valores relacionados à educação para a cidadania que, certamente, apenas as atividades de ensino e de pesquisa não proporcionariam.

A primeira edição do Programa aconteceu no ano de 2011 e se consolidou nos anos seguintes com fomentos anuais ao desenvolvimento de ações de extensão nos Campi do IFRN. O PAIE se materializa nos 21 Campi do IFRN por meio da execução de Projetos de Extensão orientados por servidores (docentes e/ou técnicos administrativos) e desenvolvido com alunos regularmente matriculados no Instituto. 0 quadro 01 mostra o quantitativo de projetos financiados pelo PAIE entre 2011 e 2017 e o quadro 02 apresenta o número de projetos financiados por Campi em 2017.

Quadro 01: quantitativo de projetos financiados pelo PAIE no período de 2011 a 2017

Fonte: elaboração própria a partir de dados fornecidos pela PROEX/IFRN

\begin{tabular}{|l|l|l|}
\hline Ano & No do Edital & Número de projetos financiados \\
\hline 2011 & Edital 02/2010-PROEX/IFRN & 64 \\
\hline 2012 & Edital No. 03/2012-PROEX/IFRN & 84 \\
\hline 2013 & Edital No. 01/2013-PROEX/IFRN & 88 \\
\hline 2014 & Edital No. 01/2014-PROEX/IFRN & 91 \\
\hline 2015 & Edital No. 01/2015-PROEX/IFRN & 97 \\
\hline 2016 & Edital No. 02/2016-PROEX/IFRN & 65 \\
\hline 2017 & Edital No. 02/2017-PROEX/IFRN & 54 \\
\hline
\end{tabular}

Quadro 02: distribuição do limite de projetos de extensão por Campi do IFRN em 2017

Fonte: Edital nº 02/2017/PROEX/IFRN

\begin{tabular}{|l|l|l|}
\hline ITEM & CAMPUS & N $^{\circ}$ MÁXIMO DE PROJETOS \\
\hline 01 & Apodi & 02 \\
\hline 02 & Caicó & 02 \\
\hline 03 & Canguaretama & 02 \\
\hline
\end{tabular}




\begin{tabular}{|c|c|c|}
\hline ITEM & CAMPUS & Nº MÁXIMO DE PROJETOS \\
\hline 04 & Ceará Mirim & 02 \\
\hline 05 & Currais Novos & 03 \\
\hline 06 & EaD & 02 \\
\hline 07 & Ipanguaçu & 03 \\
\hline 08 & João Câmara & 02 \\
\hline 09 & Lajes & 02 \\
\hline 10 & Macau & 02 \\
\hline 11 & Mossoró & 05 \\
\hline 12 & Natal-Central & 08 \\
\hline 13 & Natal-Cidade Alta & 02 \\
\hline 14 & Natal-Zona Norte & 03 \\
\hline 15 & Nova Cruz & 02 \\
\hline 16 & Parelhas & 02 \\
\hline 17 & Parnamirim & 02 \\
\hline 18 & Pau dos Ferros & 02 \\
\hline 19 & Santa Cruz & 02 \\
\hline 20 & São Gonçalo & 02 \\
\hline 21 & São Paulo do Potengi & 02 \\
\hline TOTAL DE PROJETOS & & 54 \\
\hline
\end{tabular}

A interação entre o aluno extensionista e os alunos da comunidade externa é o fator determinante da compreensão do fenômeno dessa pesquisa, visto que por meio dos processos interativos, os alunos extensionistas tem a hipótese de desenvolver novas aprendizagens que contribuem para a sua formação cidadã. Nesse sentido, Cortina (2005) argumenta que os valores morais são componentes inevitáveis do mundo humano e que portanto, a nossa vida não acontece sem eles. Os demais valores (religiosos, estéticos, saúde, intelectuais) não seriam menos importantes, mas seriam ajustados a partir dos valores morais, já que estes "atuam como integradores dos outros, não como substitutos deles." (Cortina, 2005, p. 172). Nessa mesma perspectiva, Nussbaum (2015) discorre sobre os valores que caracterizam o espírito das humanidades e defende uma educação que tenha como base um tipo de cidadania inclusiva que teria como característica o raciocínio crítico e a compreensão das experiências humanas e complexidade do mundo. Isso significa que para a escola desenvolver a educação para a cidadania, precisa formar os educandos criticamente e conscientizá-los do seu papel transformador na sociedade.

Isso implica desenvolver nos educandos as capacidades de raciocinar e refletir criticamente (Nussbaum, 2015) para que os mesmos possam viver em “[...] uma sociedade na qual as pessoas se diferenciam bastante segundo um grande número de parâmetros, entre eles religião, etnia, 
riqueza e classe, incapacidade física, gênero e sexualidade [...]. " (Nussbaum, 2015, p. 10-11)

Nesse sentido, educar para a cidadania significa educar em valores, ou seja, desenvolver situações pedagógicas que favoreçam aos educandos o cultivo de condições que os preparem para certas atitudes diante da sociedade. Segundo Cortina (2005) quando nos deparamos com algumas situações contextuais, fazemos relações que nos permitem compreendê-las, compará-las entre si ou classificá-las e partir dessas operações intelectuais decidimos o grau de importância que damos a elas, ou seja, valoramos ou não determinadas coisas. A extensão, ao inserir os alunos do ensino médio integrado em contato com a comunidade externa, possibilita aprendizados que criarão valores próprios, decorrentes dessa prática pedagógica. Dentre eles, podemos apontar a solidariedade, a criticidade, a tolerância, disponibilidade para o diálogo, autonomia, preocupação com o outro e o respeito ao próximo. (CORTINA, 2005 \& NUSSBAUM, 2015). Durante as observações realizadas entre maio e dezembro de 2017 acompanhamos o desenvolvimento dos valores acima tendo como base as indagações apresentadas no quadro 03.

Quadro 03: valores e atitudes observados entre maio e dezembro de 2017

Fonte: Elaborado pelos autores

\begin{tabular}{|c|c|c|c|}
\hline SEQ & VALORES & DESCRIÇÃO & ATITUDES/AÇÕES OBSERVADAS \\
\hline 01 & Solidariedade & $\begin{array}{l}\text { - As atividade realizadas proporcionaram } \\
\text { vivências, estudos e aprendizagens que } \\
\text { estimularam a geração de compromisso social? } \\
\text { - Os alunos extensionistas se sentem cidadãos } \\
\text { participativos na vida social da comunidade } \\
\text { externa? }\end{array}$ & $\begin{array}{l}\text { Interação entre os membros do } \\
\text { projeto; auxílio no desenvolvimento de } \\
\text { experimentos/aulas; }\end{array}$ \\
\hline 02 & Criticidade & $\begin{array}{l}\text { - Os alunos extensionistas se posicionam } \\
\text { criticamente diante de situações trazidas, } \\
\text { vividas ou apresentadas pelos participantes da } \\
\text { comunidade externa? }\end{array}$ & $\begin{array}{l}\text { Reações com tranquilidade diante de } \\
\text { questionamentos dos alunos externos; } \\
\text { capacidade de rebater conceitos e } \\
\text { opiniões; capacidade de perceber as } \\
\text { diferenças entre as escolas dos alunos } \\
\text { externos e a que estudam; }\end{array}$ \\
\hline 03 & Tolerância & $\begin{array}{l}\text { - Como ocorrem as relações no campo social } \\
\text { de interação que se estabelece entre os alunos } \\
\text { extensionistas e membros da comunidade } \\
\text { externa? }\end{array}$ & $\begin{array}{l}\text { Respostas tranquilas diante de } \\
\text { perguntas não relacionadas às } \\
\text { atividades do projeto; atitudes serenas } \\
\text { diantedecomportamentos inadequados } \\
\text { por parte dos alunos externos. }\end{array}$ \\
\hline 04 & $\begin{array}{l}\text { Disponibilidade } \\
\text { para o diálogo }\end{array}$ & $\begin{array}{l}\text { - Os alunos extencionistas se socializam no } \\
\text { interior do campo social que ocorre o processo } \\
\text { interativo proporcionado pelas atividades de } \\
\text { extensão? } \\
\text { - A forma de interação das atividades de } \\
\text { extensão favorecem a produção dialógica de } \\
\text { conhecimentos? }\end{array}$ & $\begin{array}{l}\text { Negociação de horários de chegada; } \\
\text { adiamento de atividades em função de } \\
\text { outras atividades da escola dos alunos } \\
\text { externos; conversas individuais com } \\
\text { alunos desestimulados para que não } \\
\text { desistissem; não mantiveram relações } \\
\text { autoritárias }\end{array}$ \\
\hline 05 & Preocupação & $\begin{array}{l}\text { - O discurso utilizado nas ações aponta para } \\
\text { uma visão de transformação social por meio } \\
\text { do conhecimento técnico que os alunos } \\
\text { extensionistas desenvolvem? } \\
\text { - Os alunos extensionistas demonstram aplicar } \\
\text { os seus conhecimentos técnicos em função da } \\
\text { transformação dos indivíduos da comunidade } \\
\text { externa, ou seja, o aluno extensionista } \\
\text { demonstra preocupação com a troca de } \\
\text { saberes que se estabelece entre eles? }\end{array}$ & $\begin{array}{l}\text { Atenção ao aprendizado dos alunos } \\
\text { externos; apoio individualizado aos } \\
\text { alunos externos diante de dificuldades } \\
\text { de compreensão; desenvolvimento de } \\
\text { estratégias para adequar as atividades } \\
\text { ao grau de cognição dos alunos } \\
\text { externos; tradução da linguagem } \\
\text { técnica para linguagem mais cotidiana; } \\
\text { preocupação com a ausência de alunos; } \\
\text { atenção a problemas pessoais relatos } \\
\text { pelos alunos externos; }\end{array}$ \\
\hline
\end{tabular}




\begin{tabular}{|l|l|l|l|}
\hline SEQ & VALORES & DESCRIÇÃO & ATITUDES/AÇÕES OBSERVADAS \\
\hline 06 & $\begin{array}{l}\text { Respeito ao } \\
\text { próximo }\end{array}$ & $\begin{array}{l}\text { Os alunos extensionistas respeitam as } \\
\text { posições ou limitações dos membros da } \\
\text { comunidade externa? }\end{array}$ & $\begin{array}{l}\text { Respeito às diferentes soluções/ } \\
\text { indagações/opiniões/questionamentos } \\
\text { apresentados pelos alunos externos; }\end{array}$ \\
\hline 07 & Autonomia & $\begin{array}{l}\text {-Osalunos extensionistas são capazes de tomar } \\
\text { decisões diante de situações inesperadas? }\end{array}$ & $\begin{array}{l}\text { Resolução de problemas técnicos } \\
\text { durantes as atividades sem ser } \\
\text { necessidade da intervenção/sugestão } \\
\text { do coordenador; capacidade de decidir } \\
\text { sozinhos diante de solicitações dos } \\
\text { alunos externos; }\end{array}$ \\
\hline
\end{tabular}

Os valores acima, relacionados à educação para a cidadania, foram identificados por meio de ações e atitudes que só eram possíveis de serem desenvolvidas por meio da interação proporcionada pela participação nos projetos de extensão fomentados pelo PAIE. Os vídeos gravados e as notas nos permitiram perceber como se processa o desenvolvimento das relações entre alunos extensionistas/alunos externos durante a execução de projetos de extensão do Programa de Apoio Institucional à Extensão do IFRN (Campus Mossoró). Essa relação se desenvolve em função da inserção dos alunos extensionistas em contextos e atitudes ainda não vivenciadas pelos alunos do Ensino Médio Integrado, possibilitando assim o desenvolvimento de valores relacionadas à educação para a cidadania. Portanto, podemos considerar que o PAIE é uma política de fomento do IFRN que condiz com a perspectiva de formação humana integral, além de reforçar a função social da Educação Profissional e Tecnológica ao se aproximar o Instituto da comunidade de seu entorno.

\section{CONCLUSÃO}

Compreendemos que a extensão, como princípio educativo, desenvolvida no âmbito da Rede Federal de Educação Profissional e Tecnológica, é uma prática pedagógica que, assentada nas dimensões trabalho, ciência, cultura e tecnologia, permite a socialização do conhecimento e se associa à transformação do mundo, na medida em que possibilita a interação dialógica entre educando e sociedade com o objetivo de formar integralmente o cidadão. Os valores e aprendizados desenvolvidos por meio de atividades de extensão vincula-se à produção de conhecimentos que se confrontam com a realidade, gerando no educando a capacidade crítica de não aceitação do contexto e construindo o espaço para forjar as mudanças da sociedade. O conhecimento torna-se, assim, um meio pelo qual é possível alcançar a cidadania, sendo a educação formal a mediadora entre ambos.

Nesse sentido, Xavier et al. (2013) defendem que a extensão na Rede Federal de Educação Profissional, Científica e Tecnológica "consolida a formação de um profissional cidadão e se credencia junto à sociedade como espaço privilegiado de produção e difusão do conhecimento na busca da superação das desigualdades sociais". (XAVIER et al., 2013, p. 13).

É preciso pensar na extensão como prática educativa em comunidade que "[...] colabore no aprimoramento da formação do aluno e que contribua decisivamente no manejo do conhecimento por parte da sociedade [...]" (DEMO, 2001, p. 156). Para tanto, a troca de saberes entre comunidade e 
Institutos deve se dar em uma relação dialógica articulada com a realidade socioeconômica (XAVIER et al., 2013), pois dessa forma podemos consolidar a indissociabilidade entre o ensino, pesquisa e extensão, bem como atender aos princípios da formação humana integral. Nesse contexto, inserese o Programa de Apoio Institucional à Extensão (PAIE) que visa fomentar o desenvolvimento de projetos de extensão nos Campi do IFRN. Os resultados parciais de um Estudo de Caso do Programa de Apoio Institucional à Extensão (PAIE) do IFRN no Campus Mossoró realizado entre maio e dezembro de 2017 mostram que a interação dos alunos extensionistas com alunos da comunidade externa proporcionou o desenvolvimento de valores relacionados à educação para a cidadania. As atitudes e ações observadas apontam aspectos como solidariedade, criticidade, tolerância, disponibilidade para o diálogo, preocupação, respeito ao próximo e autonomia

Esses valores, dentre outros, desenvolvidos durante a participação de alunos extensionistas do Ensino Médio Integrado em projetos de extensão fomentados pelo PAIE no Campus Mossoró, evidenciam o caráter transformador e formativo que uma política institucional de extensão pode desencadear, quando pensada como uma prática educativa por meio da interação com a comunidade externa. A inserção dos alunos em contextos diversificados e o convívio com alunos externos oriundos de outras realidades desencadeiam processos em espaços reais e comunitários que possibilitaram o desenvolvimento de valores vinculados à educação para a cidadania que não teriam sido possíveis por meio de outras práticas.

O nosso estudo vai apontando possibilidades para isso acontecer por meio dos projetos de extensão fomentados pelo PAIE. No entanto, é preciso não dissociar a extensão como princípio educativo das dimensões do ensino e da pesquisa, para esbater tradicionais preponderâncias e fragmentações de saberes, o que parece conseguir-se com sucesso se existir participação e cooperação de alunos extensionistas, alunos externos e servidores da educação profissional e tecnológica.

\section{REFERÊNCIAS BIBLIOGRÁFICAS}

1. AFONSO, N.. Investigação naturalista em educação: um guia prático e crítico. Vila Nova de Gaia: Fundação Manoel Leão, 2014.

2. BRASIL. Lei no 11.892, de 29 de dezembro de 2008. Institui a Rede Federal de Educação Profissional, Científica e Tecnológica, cria os Institutos Federais de Educação, Ciência e Tecnologia, e dá outras providências. Diário Oficial [da República Federativa do Brasil], Brasília, DF, n. 253, p. 1, dez. 2008. Seção 1.

3. CEFET-RN. Resolução $n^{\circ}$. 35, de 22 de novembro de 2006. Aprovar, na forma do anexo, as Normas para as Atividades de Extensão do Centro Federal de Educação Tecnológica do Rio Grande do Norte. Natal, RN: CEFET. Disponível em: <http://portal.ifrn.edu.br/extensao/ resolucoes/resolucao-no-35-de-22-de-novembro-de-2006> Acesso em: 07 mar. 2018.

4. CORTINA, A.. Cidadãos do mundo: para uma teoria da cidadania. São Paulo: Edições 
Loyola, 2005.

5. COVER, I.. Práticas de extensão no ensino médio integrado : construindo possibilidades de emancipação. Florianópolis: ANPED, 2014. Disponível em: <http://xanpedsul.faed.udesc.br/ arq_pdf/485-0.pdf> Acesso em: 09 set. 2017.

6. DEMO, P.. Lugar da extensão. In: FARIA, D. S. de. (Ed.), Construção Conceitual da Extensão Universitária na América Latina. Brasília: UNB, 2001.

7. FREIRE, P. (1996). Pedagogia da autonomia: saberes necessários à prática educativa. Rio de Janeiro: Paz e terra.

8. FREIRE, P. Extensão ou comunicação? (17 ed.). São Paulo: Paz e terra, 2015.

9. IFRN. Resolução $n^{\circ}$ 66, de 31 de agosto de 2009. Aprova o estatuto do Instituto Federal de Educação, Ciência e Tecnologia do Rio Grande do Norte. Natal, RN: IFRN. Disponível em: <http://portal.ifrn.edu.br/institucional/normas-e-leis/Resolucao\%20n.66.zip/at_download/file> Acesso em: 08 mar. 2018.

10. NUSSBAUM, M.. Sem fins lucrativos: por que a democracia precisa das humanidades. São Paulo: Editora WMF Martins Fontes, 2015.

11. PACHECO, E.. Institutos Federais uma Revolução na Educação Profissional e Tecnológica. Brasília, São Paulo: Fundação Santillana, Editora Moderna, 2011.

12. SIMONS, H.. Case study research: In-depth understanding in context. In: LEAVY, P. (Ed.), The Oxford Handbook of Qualitative Research (pp. 455-470). New York: Oxford University Press, 2014.

13. SOUSA, A. L. L.. Concepção de extensão universitária: ainda precisamos de falar sobre isso? In: FARIA, D. S. de. (Ed.), Construção conceitual da extensão universitária na América Latina. Brasíla: UNB, 2001.

14. TAVARES, M. das G. M.. Os múltiplos conceitos de extensão. In: FARIA, D. S. de. (Ed.), Construção conceitual da extensão universitária na América Latina. Brasíla: UNB, 2001.

15. XAVIER A. C. G. et al. Concepções, diretrizes e indicadores da extensão na Rede Federal de Educação Profissional, Científica e Tecnológica - EPCT. In: Extensão tecnológica: rede federal de educação profissional, científica e tecnológica. Cuiabá: CONIF/IFMT, 2013. 